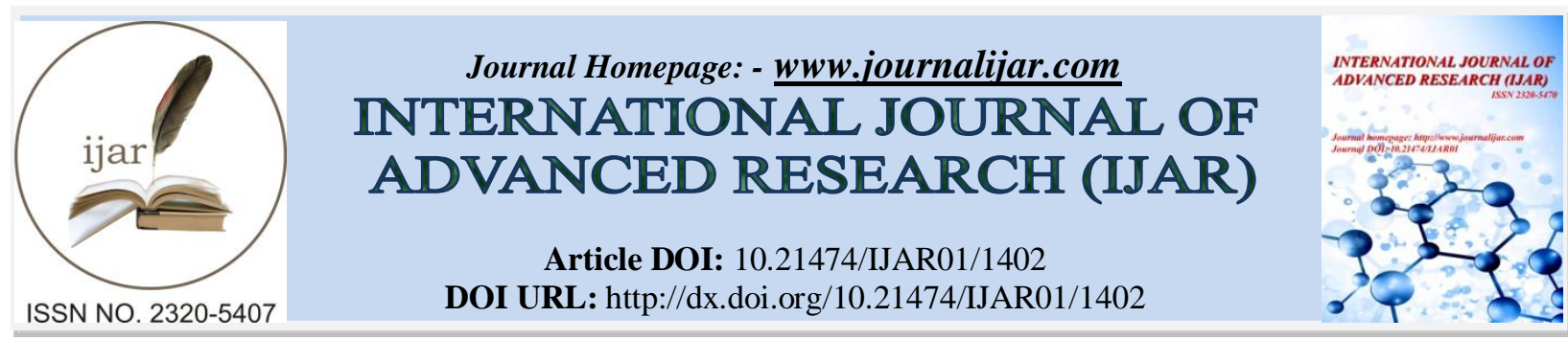

RESEARCH ARTICLE

\title{
STUDY OF CELL FREE MITOCHONDRIAL DNA CONTENT OF EMBRYO CULTURE MEDIUM AT DAY 3 AND BLASTOCYST DEVELOPMENT AND QUALITY DURING INTRACYTOPLASMIC SPERM INJECTION CYCLES.
}

\author{
"Azza A. Abdel Razik', Manal O. El Hamshary², Magd Eldin M. Mohamed ${ }^{1}$, Yousef Adel Soliman ${ }^{3}$ and \\ Omima A. Khamiss ${ }^{2}$. \\ 1. Department of obstetrics and gynecology, Ain Shams University, Egypt. \\ 2. GEBRI, Sadat City University, Egypt. \\ 3. Central Lab. For evaluation of Veterinary Biologics (CLEVB), Egypt.
}

\section{Manuscript Info}

Manuscript History

Received: 18 June 2016

Final Accepted: 19 July 2016

Published: August 2016

Key words:-

Semiconductor, Photocatalysis, sensors, memory devices.

\section{Abstract}

Background: The morphological criteria are still the main method during In Vitro Fertilization (IVF) technology for selection of human embryos with possible high implantation rates and successful pregnancy potential. Embryo fragmentation is routinely used as the main tool for grading the human embryo and its implantation potential. Fragments of human embryo cells are the sources of cell free mitochondrial DNA (mtDNA) that released into the embryo culture media (secretome). Cell free mtDNA detection in human embryo secretome can be used as a non invasive objective tool to appraise the fragmentation of the embryo cells and thus the growing potential to the blastocyst stage .

Aim: the aim of the present research paper was to evaluate the correlation between cell free Mitochondrial DNA content of embryo culture medium at Day 3 and blastocyst growth and grading during Intracytoplasmic Sperm Injection (ICSI) cycles.

Subjects and Methods: 50 spent embryo culture media were collected from 17 ICSI cycles. In twenty good quality grade 1 embryos; culture samples were collected and embryos allowed continuing in culture to reach blastocyst stage. After extraction and purification; mitochondrial DNA was profiled by specific semi quantitative method (Agarose gel electrophoresis). Each Day 3 embryo was morphologically graded according to the current consensus system (Alpha Scientists in Reproductive Medicine and ESHRE Special Interest Group of Embryology, 2011. At D5 blastocysts were morphologically scored according to criteria described by Gardner and Schoolcraft (1999) and recently agreed by an expert panel of scientists (Alpha Scientists in Reproductive Medicine and ESHRE Special Interest Group of Embryology, 2011).

Results: Insignificant correlation was found between mtDNA profiling in D3culture media of embryonic development and embryo 
fragmentation, but when correlating mtDNA profile on D3 and embryo fragmentation and grade; highly significant correlation was found with embryos of G2 or lower quality. Significant correlation was detected between free mtDNA amount and blastocyst formation. Also , a highly significant correlation was noticed between mtDNA profiling on D3 for those embryos and their blastocyst grading in D5.

Conclusion -:Results of the current study are suggestive of a significant correlation between the human embryo culture media mtDNA profile in D3 and the degree of embryo blastomeres fragmentation especially in bad quality embryos; with significant correlation between mtDNA profiling and blastocyst formation and quality in Day5.

Copy Right, IJAR, 2016,. All rights reserved.

\section{Introduction:-}

Embryo quality is crucial to the pregnancy rate results of IVF; however ,the ability to sharply distinguish the embryos with higher reproductive potential from others is poor. The culture medium is the immediate near environment of the embryos in vitro, and any change of the materials in the culture medium may possibly relate to the embryo grading and quality.

Routinely ,embryo selection for transfer in utero is mainly depending on morphological and developmental criteria such as the degree of fragmentation, blastomeres size and multinucleation, embryo symmetry and cleavage rate, which are assessed at few predetermined microscope evaluations on Day 2or 3 post-insemination (Alpha Scientists in Reproductive Medicine and ESHRE Special Interest Group of Embryology, 2011).

The elevated incidence of pregnancy complications and neonatal problems associated with a high-twinning rate after IVF can only be successfully reduced by the transfer of one embryo. However, to date, there is no non-invasive platform that has been proven to be of true clinical predictive value or been examined in prospective randomized controlled trials to be better than current morphology-based selections methods (Hardarson et al., 2012 ; Vergouw et al., 2012).

It was previously discovered that both genomic (DNA) gDNA, and mitochondrial DNA (mtDNA) are detectable in the secretome of human cleavage-stage embryos (Stigliani et al., 2013). Since widespread fragmentation is often associated with genetic abnormalities, i.e. aneuploidy and mosaicism (Sathananthan et al., 1990 ;Pellestor et al., 1994a, b; Munne 'et al., 1995; Ebner et al., 2001; Chavez et al., 2012); it has been hypothesized that fragmentation is the manifestation of a defective embryogenesis and possibly bad quality embryos with low pregnancy potential. Alternatively ,fragmentation could result in loss of whole blastomeres, loss of cytoplasm from individual blastomeres or both, and deplete the embryos of essential organelles (Pereda and Croxatto, 1978; Lehtonen, 1980; Ebner et al., 2001), such as mitochondria .

Consistent with this, fragmented embryos may have lower mitochondrial DNA (mtDNA) levels (Lin et al., 2004) and a different mitochondrial distribution pattern compared with non-fragmented embryos (Wilding et al., 2001). This pattern may be linked to reduced adenosine triphosphate content and reduced developmental potential (Van Blerkom et al.(1995,.

Since mitochondrial functions are critical during the first few days of life, we were interested in carrying out this research of studying mtDNA levels in human embryo cultures during pre-implantation stage and check new objective tool for detecting the D3 embryos which can reach blastocyst stage at D5 with good quality.

\section{Materials and Methods:-}

The study is a prospective cohort observational study, evaluating the possible clinical use of the profile of cell-free mtDNA released by human embryos into their culture medium as a correlated criterion with embryo morphological features. Fifty embryo spent culture media samples taken from 17 patients undergoing ICSI treatment cycles in Ain 
Shams University Assisted Reproduction Unit, Cairo-Egypt. Written informed consent was obtained for the use of embryo culture media samples at Day3.The local Institutional Review Board approved the study .Cryopreserved gametes and all oocytes inseminated by conventional IVF were excluded from the study, in order to avoid potential biases due to cooling/thawing procedures and potential contaminating DNA from spermatozoa, respectively.

\section{Patients' Characteristics:-}

The women's age mean $\pm \mathrm{SD}$ : was $(30.3 \pm 6.0$ years $)$ and their body mass index (BMI) mean \pm SD: was $(27.5 \pm$ $4.6 \mathrm{~kg} / \mathrm{m} 2$ ). In this study, female infertility was the cause of the consultation for $64 \%$ of couples; male factors for $42 \%$; mixed infertility for $43 \%$ and unexplained infertility for $5 \%$. The baseline hormonal status was evaluated in each patient at Day 3 of the cycle. (Table 1)

All the ICSI cycles completed during the studY were conducted according the identical approved assisted reproduction unit of Ain Shams University treatment protocol; the long mid-luteal gonadotropins releasing hormone (GnRh) agonist (Triptoreline, $0.1 \mathrm{mg} \mathrm{SC}$ per day; (Decapeptyl; Ipsen S.p.A., Milan, Italy) was given starting on day 18 of the preparation cycle) down regulation protocol. When the down-regulation had been confirmed by serum E2 levels of $<50 \mathrm{pg} / \mathrm{mL}$, ovarian hyperstimulation was started on cүcle day 3 of the menstrual cycle on wards by oncedaily injection of a highly purified hMG (Menogon hP, Ferring, Kiel, Germany) at a dose determined by the physician, based on the patient's characteristics and history When at least three Graffian follicles reached $18 \mathrm{~mm}$ in mean diameter, transvaginal oocyte retrieval (оосүte ріск-up) and follicular fluid collection was initiated 3436 hours following ovulation triggering by administration of 10,000 IU of human chorionic gonadotropins (hCG); (Chriomon, 10,000 IU; IBSA, Switzerland).

Global total media for culture (Global Total, Life Global Europe, Rue de la Presse 4, 1000 Brussels Belgium) and Irvine sperm wash media for semen preparation (Irvine Scientific, Santa Ana, USA) were used during the ICSI procedure.

On Day 3, following removal of the embryos in preparation for transfer into the blastocyst medium or into the uterine cavity, 20 microliter spent culture media from each embryo were collected into sterile, DNA-, DNase-, RNase-, polymerase chain reaction(PCR) inhibitors-free tubes (Eppendorf, Hamburg, Germany) and immediately stored at $-20 \mathrm{C}$ until nucleic acid purification. Appropriate precautions were taken to prevent contamination of samples by extraneous cells or DNA. During each experimental step, laboratory personnel wore gloves and coat, and physical isolation was guaranteed by working in clean air hoods.

Each Day 3 embryo was morphologically scored according to the current consensus system (Alpha Scientists in Reproductive Medicine and ESHRE Special Interest Group of Embryology, 2011) by combining the number and size of blastomeres, the degree of fragmentation and the cleavage rate.Embryos if few in number or with low grade quality were transferred to uteri at D3. On the other hand in cases with good number of embryos and / or good quality ones; the embryos were allowed to grow in media to Day 5 (blastocyst stage) then scored and transferred to uteri. The Gardner blastocyst grading sYstem (2000) was used to evaluate blastocysts using 3 separate quality scores to each blastocyst embryo:

1.Blastocyst development stage - expansion and hatching status

2.Inner cell mass (ICM) score, or quality

3.Trophectoderm (TE) score, or quality.

\section{Materials:-}

Extraction and purification of the free circulating DNA:-

QIAamp Circulating Nucleic Acid Kit (Qiagen cat \# 55114)

Absolute ethanol -for HPLC, gradient grade, $\geq 99.8 \%$ (Fluka Cat \# 02854 )

\section{Amplification of human mitochondrial DNA from:-}

REPLI-g Mitochondrial DNA Kit (Qiagen cat \# 151023)

\section{Buffers and reagents used for agarose gel electrophoresis:-}

(Sambrook et al., 1988)

Ethedium bromide $(\mathrm{EBr})$ : It was prepared in stock solution, $10 \mathrm{mg} / \mathrm{ml}$ by dissolving one tablets $(10 \mathrm{mg} / \mathrm{tab}) \mathrm{in} 1 \mathrm{ml}-$ distilled water, vortex, stored in dark at $+4 \mathrm{oC}$. To be used at $0.5 \mathrm{ug} / \mathrm{ml}$ final concentration. 
The solution was heated but not boiled in a microwave till dissolving, left to cool to $60 \mathrm{oC}$, and then $5 \mathrm{ul}$ of $\mathrm{EBr}$ solution was added. The solution was poured in the casting tray of electrophoresis apparatus and left to solidify.

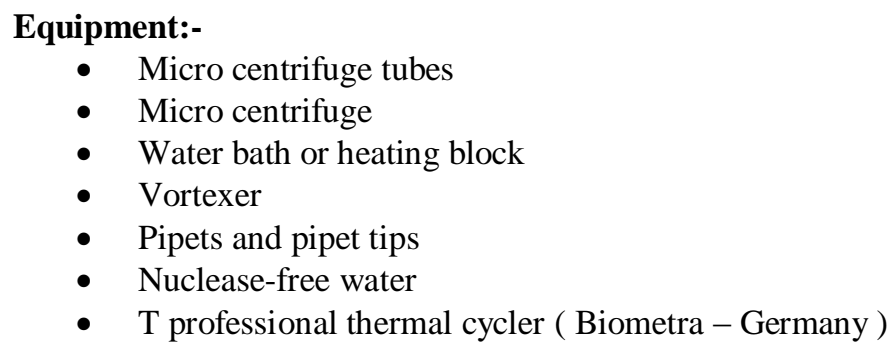

Methods:-

Extraction and purification of the free circulating DNA:-

It was done according to the manufacture instructions. All the sample volumes were adjusted to $1000 \mu \mathrm{l}$ with

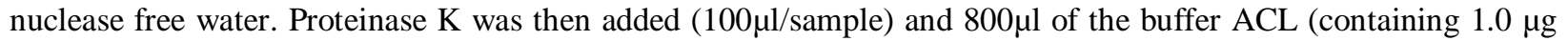
carrier RNA), the whole mixture was incubated in water bath at $60{ }^{\circ} \mathrm{C} / 30 \mathrm{~min}$. To the lysate $1.8 \mathrm{ml}$ of buffer ACB was added and mixed thoroughly by pulse-vortexing for 15-30 s. The whole lysate was then transferred to the QIAamp Mini column and subjected to vacuum at a rate of -800 to -900 mbar, after the whole fluid have been drawn off, the columns were washed once with $600 \mu$ l of ACW1 then with $750 \mu$ of ACW2 buffer and finally with $750 \mu \mathrm{l}$ of absolute ethanol. The column was then dried by centrifugation at $14000 \mathrm{rpm} / 5 \mathrm{~min}$ and then left at $60{ }^{\circ} \mathrm{C}$ for further $5 \mathrm{~min}$ to insure complete dryness. The DNA was then eluted with $20 \mu \mathrm{l}$ of AVE buffer by centrifugation at $14000 \mathrm{rpm} / 1 \mathrm{~min}$. eluted DNA was stored at $-20{ }^{\circ} \mathrm{C}$ till used.

\section{Amplification of mitochondrial DNA:-}

It was done according to the manufacture instructions. The purified DNA was first thawed on ice then $10 \mu$ of each sample was mixed with equal volume of nuclease free water and $29 \mu \mathrm{l}$ of the amplification mix ( $27 \mu \mathrm{l}$ of reaction buffer and $2 \mu \mathrm{l}$ of the primer mix) the mixture was then vortexed and centrifuged briefly.

The samples were incubated for $5 \mathrm{~min}$ at $75^{\circ} \mathrm{C}$ and allowed to cool down to room temperature $\left(15-25^{\circ} \mathrm{C}\right)$. Then $1 \mu 1$ REPLI-g Midi Polymerase was added to each sample and incubated at $33^{\circ} \mathrm{C}$ for $8 \mathrm{~h}$ in the thermal cycler. The enzyme was then inactivated at $65^{\circ} \mathrm{C} / 3 \mathrm{~min}$ and the reaction mix was then stored at $-20^{\circ} \mathrm{C}$ till used.

\section{Agarose gel electrophoresis:-}

According to Sambrook et al. (1989) To assess the PCR product, $4 \mathrm{~mm}$ thickness of $1 \%$ Agarose containing $0.5 \mu \mathrm{g} / \mathrm{ml} \mathrm{EBr}$ was poured in mini-gel and left till solidify before submarine loading of $8 \mu \mathrm{l}$ of PCR-product mixed with $2 \mu 1$ of DNA loading buffer. Three $\mu \mathrm{l}$ of $100 \mathrm{bp}$ DNA ladder in $1 \mu \mathrm{l}$ loading buffer were used as DNA marker. DNA was electrophoresed at $80 \mathrm{v} / 15$ minutes and finally examined using UV trans-illuminatore.

\section{Results interpretation:-}

Agarose gel electrophoresis revealed the amplification of the mtDNA from many samples but with different concentrations (the intensity of the bands were vary greatly) and some other sample failed to give a positive amplicon. In order to perform the non-parametric statistical analysis; the results were ranked as shown in (Table 2).

\section{Results:-}

In 12 samples (24\%) mtDNA was undetectable. Thirty eight (76\%) samples showed variable amounts of mtDNA; 6 samples with mild mtDNA profile, 21 samples with moderate mtDNA profile and 11 samples showed severe mtDNA fragmentation profile. (Table3) Each embryo was morphologically scored and graded on D3 with blastomeres fragmentation recording. Grade one embryos with the least fragmentation amount were 20 embryos. Those embryos were not transferred and allowed to continue development to Day 5 and mtDNA profiling for their spent culture media were evaluated. The remaining 30 embryos were scored as follows: 14 embryos were G2, 10 embryos were G3 and 6 embryos were G4 .

Insignificant correlation was found between mtDNA profiling in D3 of embryonic development of the whole study samples and embryo fragmentation and grading $(\mathrm{P}$ value $=0.221)$. Table $4 \& 5$ and Figure 1 and 2. 
Highly significant correlation was found when correlating mtDNA profile on D3 and embryo fragmentation and or embryo grade; for embryos of G2 or lower quality (P value $=<0.001$ ). Table 6

That is to say; semi quantification of mtDNA profiles of human embryo culture media in relation to embryo grading and fragmentation revealed those high levels of mtDNA fragmentation with poor lower embryo quality. In twenty good quality grade 1 embryos culture samples which allowed continuing in culture to reach blastocyst stage ; significant correlation was found between mtDNA fragmentation profiling and blastocyst formation inD5. (Table 7)

Also ,a highly significant correlation was detected between mtDNA fragmentation profiling on D3 and blastocyst grading in D5 .(Table 8)

Significant correlation was also found between the following patients 'variables and mtDNA profile of embryo culture media on D3: age of the patient, base line E2, previous ICSI trials, numbers of gonadotropins stimulation days and fertilization rate. (Table 9)

Receiver operating characteristic (ROC) curve derived from the multivariable binary logistic regression model for prediction of the producing of grade 1 or 2 embryos reveled sensitivity of 79.4 and specificity 93.7 ( Figure 3).

Table 1:- Characteristics of the study population.

\begin{tabular}{|l|l|}
\hline Variable & Value \\
\hline Age $($ years $)$ & $30.3 \pm 6.0$ \\
\hline BMI $\left(\mathrm{kg} / \mathrm{m}^{2}\right)$ & $27.5 \pm 4.6$ \\
\hline Baseline FSH $(\mathrm{mIU} / \mathrm{l})$ & $6.0 \pm 2.6$ \\
\hline Baseline $\mathrm{LH}(\mathrm{mIU} / \mathrm{l})$ & $6.1 \pm 4.5$ \\
\hline Baseline E2 $(\mathrm{pg} / \mathrm{ml})$ & $45.4 \pm 21.2$ \\
\hline Follow-up time & \\
\hline Up to D3 & 30 cases $(60.0 \%)$ \\
\hline Up to D5 & 20 cases $(40.0 \%)$ \\
\hline
\end{tabular}

Data are mean \pm SD or number $(\%)$

Table 2:- Rank of the non-parametric statistical analysis of the results.

\begin{tabular}{|l|l|}
\hline- & No amplification corresponding to no DNA fragmentation \\
\hline+ & Mild DNA fragmentation (profile) \\
\hline++ & Moderate DNA fragmentation (profile) \\
\hline+++ & Severe DNA fragmentation (profile) \\
\hline
\end{tabular}

Table 3:- DNA profile on D3 in the study population

\begin{tabular}{|l|l|}
\hline Variable & Value \\
\hline DNA profile on D3 & \\
\hline Nil & $12(24.0 \%)$ \\
\hline Mild & $6(12.0 \%)$ \\
\hline Moderate & $21(42.0 \%)$ \\
\hline Severe & $11(22.0 \%)$ \\
\hline
\end{tabular}

Data are number $(\%)$.

Table 4:- Relation between the DNA profile and degree of fragmentation on D3.

\begin{tabular}{|l|l|l|l|l|l|l|l|}
\hline \multicolumn{2}{|l|}{ DNA profile on D3 } & & & \\
\hline Variable & Nil (n=12) & Mild (n=6) & $\begin{array}{l}\text { Moderate } \\
(\mathbf{n = 2 1})\end{array}$ & $\begin{array}{l}\text { Severe } \\
(\mathbf{n = 1 1})\end{array}$ & $\chi^{2}$ & DF & $\begin{array}{l}\text { p- } \\
\text { valueđI }\end{array}$ \\
\hline $\begin{array}{l}\text { Degree of fragmentation } \\
\text { on D3 }\end{array}$ & & & & & 1.498 & 1 & 0.221 \\
\hline Nil & $3(25.0 \%)$ & $1(16.7 \%)$ & $11(52.4 \%)$ & $5(45.5 \%)$ & & & \\
\hline Mild & $8(66.7 \%)$ & $5(83.3 \%)$ & $1(4.8 \%)$ & $0(0.0 \%)$ & & & \\
\hline Moderate & $1(8.3 \%)$ & $0(0.0 \%)$ & $6(28.6 \%)$ & $3(27.3 \%)$ & & & \\
\hline Severe & $0(0.0 \%)$ & $0(0.0 \%)$ & $3(14.3 \%)$ & $3(27.3 \%)$ & & & \\
\hline
\end{tabular}


Data are number $(\%)$.

$\chi^{2}$, Chi-squared statistic;

DF, degree of freedom.

IIChi-squared test for trend.

Table 5:- Relation between the DNA profile and embryo grade on D3.

\begin{tabular}{|l|l|l|l|l|l|l|l|}
\hline \multicolumn{5}{|l|}{ DNA profile on D3 } & & & \\
\hline Variable & Nil (n=12) & Mild (n=6) & Moderate (n=21) & Severe (n=11) & $\chi^{2}$ & DF & p-valueII \\
\hline Embryo grade on D3 & & & & & 1.772 & 1 & 0.183 \\
\hline Grade 1 & $3(25.0 \%)$ & $1(16.7 \%)$ & $11(52.4 \%)$ & $5(45.5 \%)$ & & & \\
\hline Grade 2 & $2(16.7 \%)$ & $1(16.7 \%)$ & $3(14.3 \%)$ & $1(9.1 \%)$ & & & \\
\hline Grade 3 & $5(41.7 \%)$ & $1(16.7 \%)$ & $3(14.3 \%)$ & $4(36.4 \%)$ & & & \\
\hline Grade 4 & $2(16.7 \%)$ & $3(50.0 \%)$ & $4(19.0 \%)$ & $1(9.1 \%)$ & & & \\
\hline
\end{tabular}

Data are number $(\%)$.

$\chi^{2}$, Chi-squared statistic;

DF, degree of freedom.

IIChi-squared test for trend.

Table 6:- Relation between the DNA profile and embryo grade on D3 in the subgroup of patients with G2 or lower quality embryos on D3.

\begin{tabular}{|l|l|l|l|l|l|l|l|}
\hline & \multicolumn{2}{|l|}{ DNA profile on D3 } & & & \\
\hline Variable & Nil (n=9) & Mild (n=5) & Moderate $(\mathrm{n}=10)$ & Severe $(\mathrm{n}=6)$ & $\chi^{2}$ & DF & p-valueII \\
\hline Embryo grade on D3 & & & & & 16.461 & 1 & $<0.001$ \\
\hline Mild & $8(88.9 \%)$ & $5(100.0 \%)$ & $1910.0 \%)$ & $0(0.0 \%)$ & & & \\
\hline Moderate & $1(11.1 \%)$ & $0(0.0 \%)$ & $6(60.0 \%)$ & $3(50.0 \%)$ & & & \\
\hline Severe & $0(0.0 \%)$ & $0(0.0 \%)$ & $3(30.0 \%)$ & $3(50.0 \%)$ & & & \\
\hline
\end{tabular}

Data are number $(\%)$.

$\chi^{2}$, Chi-squared statistic;

DF, degree of freedom.

TIChi-squared test for trend.

Table 7:- Relation between the DNA profile on D3 and blastocyst formation on D5

\begin{tabular}{|c|c|c|c|c|c|c|c|}
\hline & \multicolumn{4}{|c|}{ DNA profile on D3 } & \multirow[b]{2}{*}{$\chi^{2}$} & \multirow[b]{2}{*}{ DF } & \multirow[b]{2}{*}{ p-value $\llbracket$} \\
\hline Variable & $\begin{array}{l}\text { Nil } \\
(n=3)\end{array}$ & Mild (n=1) & $\begin{array}{l}\text { Moderate } \\
(\mathbf{n}=11)\end{array}$ & $\begin{array}{l}\text { Severe } \\
(\mathbf{n}=5)\end{array}$ & & & \\
\hline $\begin{array}{l}\text { Blastocyst formation } \\
\text { onD5 }\end{array}$ & & & & & 3.280 & 1 & 0.007 \\
\hline No blastocyst formation & $0(0.0 \%)$ & $0(0.0 \%)$ & $6(54.5 \%)$ & $3(60.0 \%)$ & & & \\
\hline Blastocyst formation & $3(100.0 \%)$ & $1(100.0 \%)$ & $5(45.5 \%)$ & $2(40.0 \%)$ & & & \\
\hline
\end{tabular}

Data are number (\%).

$\chi^{2}$, Chi-squared statistic;

DF, degree of freedom.

IIChi-squared test for trend.

Table 8:- Relation between the DNA profile on D3 and the blastocyts grade on D5.

\begin{tabular}{|c|c|c|c|c|c|c|c|}
\hline & \multicolumn{4}{|c|}{ DNA profile on D3 } & \multirow[b]{2}{*}{$\chi^{2}$} & \multirow[b]{2}{*}{ DF } & \multirow[b]{2}{*}{ p-valued } \\
\hline Variable & Nil $(n=3)$ & Mild (n=1) & Moderate $(n=5)$ & Severe $(n=2)$ & & & \\
\hline Blastocyst grade on D5 & & & & & 8.420 & 1 & 0.004 \\
\hline Grade 1 & $3(100.0 \%)$ & $0(0.0 \%)$ & $0(0.0 \%)$ & $0(0.0 \%)$ & & & \\
\hline Grade 2 & $0(0.0 \%)$ & $1(100.0 \%)$ & $1(20.0 \%)$ & $0(0.0 \%)$ & & & \\
\hline Grade 3 & $0(0.0 \%)$ & $0(0.0 \%)$ & $4(80.0 \%)$ & $2(100.0 \%)$ & & & \\
\hline
\end{tabular}

Data are number (\%).

$\chi^{2}$, Chi-squared statistic;

DF, degree of freedom.

IIChi-squared test for trend. 
Table 9:- Correlation between the Embryo grade on D3 and other relevant variables.

\begin{tabular}{|l|l|l|l|}
\hline & Embryo grade on D3 & \\
\hline Variable & Number & Spearman rho ( $\rho)$ & p-valueII \\
\hline Age (years) & 50 & -0.336 & $\mathbf{0 . 0 1 7}$ \\
\hline Baseline E2 (pg/ml) & 50 & -0.288 & $\mathbf{0 . 0 4 3}$ \\
\hline Number of previous IVF trials & 50 & -0.296 & $\mathbf{0 . 0 3 7}$ \\
\hline Number of stimulation days & 50 & -0.346 & $\mathbf{0 . 0 1 4}$ \\
\hline Fertilization rate & 50 & -0.336 & $\mathbf{0 . 0 1 7}$ \\
\hline DNA profile on D3 & 50 & -0.195 & 0.174 \\
\hline
\end{tabular}

ISpearman rank correlation.

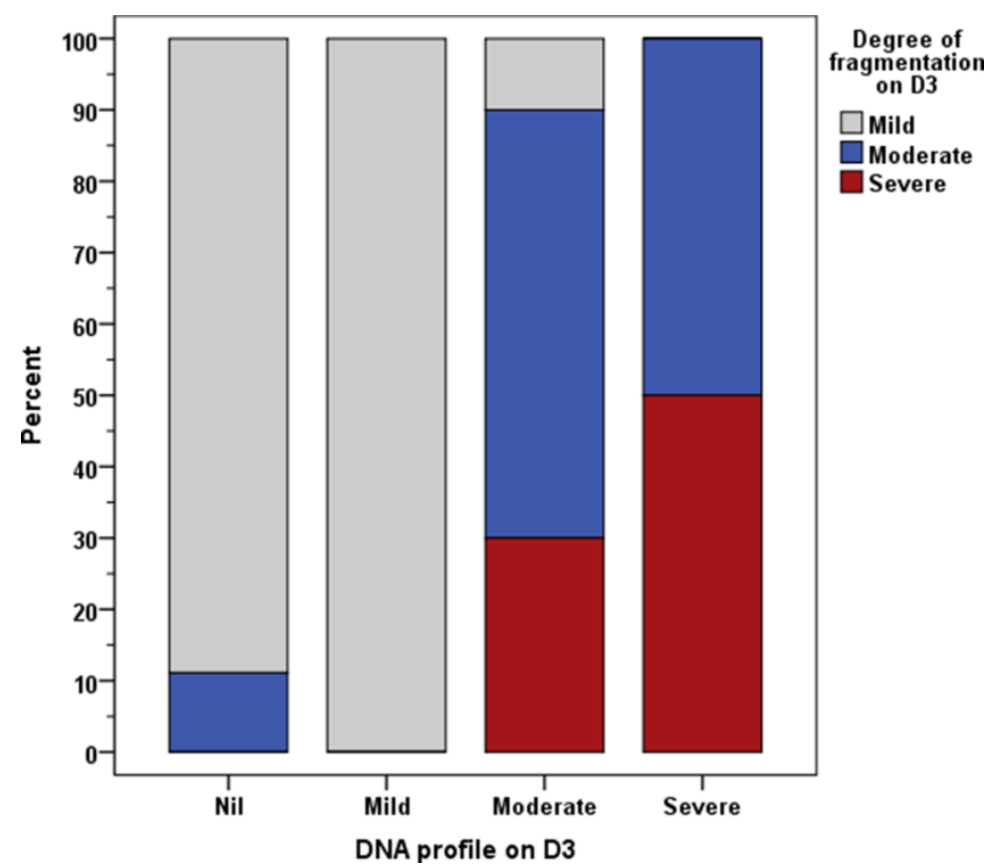

Figure 1:- Relation between the DNA profile and degree of fragmentation on D3.

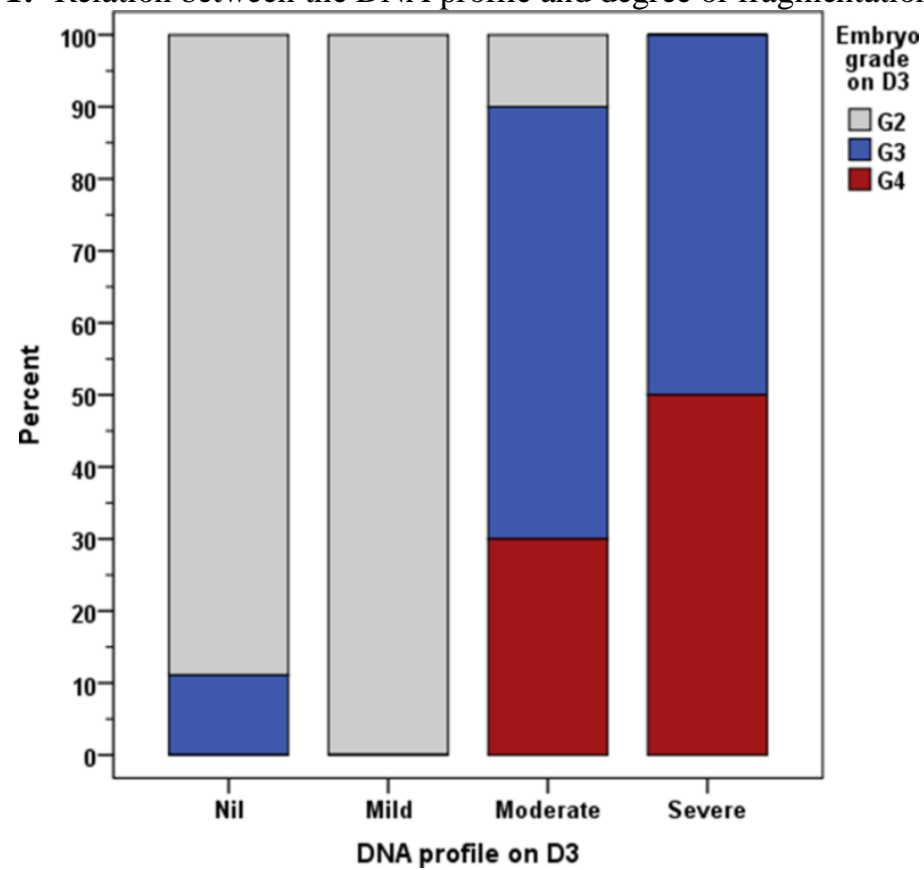

Figure 2:- Relation between the DNA profile and embryo grade on D3. 


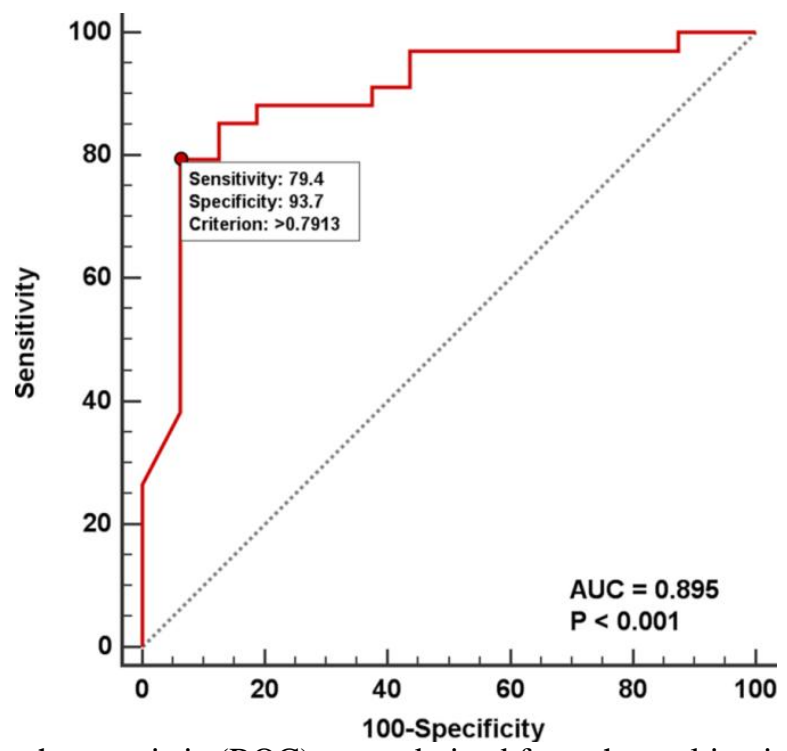

Figure 3:- Receiver operating characteristic (ROC) curve derived from the multivariable binary logistic regression model for prediction of the producing of grade 1 or 2 embryos.

\section{Discussion:-}

It is known that replication of mitochondrial genome is strictly regulated during development, passing from primordial germ cells into oocytes and then, through the embryo and the fetus, into mature cells (St John, 2014). The presence of high mtDNA concentrations in spent culture medium of human growing embryos could be the consequence but also one of the causes of poor embryo quality.

The study idea emerged from the hypothesis that embryo cells fragmentation should reflect the release of mitochondrial and/or nuclear DNA into the embryo culture medium and may establish a positive association between mtDNA profiles and embryo early in-vitro development.

The results of the present study show that mtDNA levels in human embryo culture media samples were correlated with embryo fragmentation extent and also were associated with embryo quality and grading. Our data suggest that human embryo culture media mtDNA levels could be used to predict objectively embryo quality at Day 3 especially in bad quality embryos. We found also human embryos that show competence for blastocyst development and reached day 5 had low mtDNA profiles and that was different when compared with those embryos with lower quality that transferred at Day 3 and had high mtDNA profiles in their secretome. After all, in our cohort of samples, blastulation mostly occurred in top-quality embryos, with no or a mild degree of fragmentation , that is in agreement with the fact that the loss of cytoplasm from blastomeres is detrimental for embryo competence (Ebner et al., 2001). Taken together, our results and previously published data suggest that cell free mtDNA quantification in human embryo culture media could give a better predictive picture of embryo quality and fragmentation, and could be used in future in addition to the subjective morphological criteria.

Our research data suggest that mtDNA profile assessment in spent culture media, in combination with morphological grading, may provide additional information for selection of Day 3embryos with high implantation potential. Ideally, a major benefit of this approach would be to perform elective single-embryo transfers on Day 3, without losing the advantages of a transfer at blastocyst stage in Day5, and , at the same time, preventing the drawbacks of an extended embryo culture .

Further randomized prospective studies on larger number of samples, mainly focused on implantation results, will have to be conducted, with the aim at determining usefulness and limitations of the mtDNA quantification in the embryo selection criteria. Moreover, if further studies will show that high mtDNA levels contribute to poor embryo quality, it could be possible to investigate the possibility of therapeutic approaches based on DNase treatment to reduce cell free DNA concentration with the final aim of improving assisted reproductive techniques outcome . 


\section{Conclusion:-}

This preliminary data suggest that mtDNA level assessment in spent embryo media ,in combination with morphological grading, may provide adjuvant information for selection of Day 3embryos with good quality and high implantation potential. In summary, the results of this study demonstrate that mtDNA level assessment in spent culture media in Day 3 embryo secretome, in combination with morphological grading may have the potential to improve proper identification of good quality embryos with high developmental and pregnancy rate potential .

\section{Acknowledgment:-}

Authors are grateful to Prof .Gamal F. Mustafa (Department of obstetrics and gynecology, Ain Shams University, Egypt) for his contribution in manuscript drafting and critical discussion. All authors read and approved the manuscript.

Conflict of interest: Authors declare no conflicts of interest .

\section{Conflict of interest:-}

Authors declare no conflicts of interest.

\section{References:-}

1. Alpha Scientists in Reproductive Medicine and ESHRE Special Interest Group of Embryology. The Istanbul consensus workshop on embryo assessment: proceedings of an expert meeting. Hum Reprod. 2011; 26:1270-1283.

2. Ebner T, Yaman C, Moser M, Sommergruber M, Polz W, Tews G. Embryo fragmentation in vitro and its impact on treatment and pregnancy outcome. FertilSteril. 2001; 76: 281-285.

3. Chavez SL, Loewke KE, Han J, Moussavi F, Colls P, Munne S, Behr B, Reijo Pera RA. Dynamic blastomere behavior reflects human embryo ploidy by the four-cell stage. Nat Commun. 2012;3:1251.

4. Fujimoto VY, Browne RW, Bloom MS, Sakkas D, Alikani M. Pathogenesis, developmental consequences, and clinical correlations of human embryo fragmentation. FertilSteril. 2011; 95:1197-1204.

5. Hardarson T, Ahlstrom A, Rogberg L, Botros L, Hillensjo T,Westlander G, Sakkas D, Wikland M. Non-invasive metabolomic profiling of Day 2 and 5 embryo culture medium: a prospective randomized trial. Hum Reprod. 2012; 27:89-96.

6. Lin, HV, Rogulja A, Cadigan KM. Wingless eliminates ommatidia from the edge of the developing eye through activation of apoptosis. Development. 2004; 131(10): 2409-2418

7. Munne S, Alikani M, Tomkin G, Grifo J and Cohen J. Embryo morphology, developmental rates and maternal age are correlated with chromosome abnormalities. Fertil.Steril.1995; 64: 382-391.

8. Pellestor F, Dufour MC, Arnal F. and Humeau C. Direct assessment of the rate of chromosomal abnormalities in grade IV human embryos produced by in-vitro fertilization procedure. Hum. Reprod. 1994a; 9:293-302.

9. Pellestor F, Girardet A, Andreo B, Arnal F and Humeau C. Relationship between morphology and chromosomal constitution in human preimplantationembryo. Mol. Reprod. Dev.1994b; 39:141-146.

10. Sambrook J, Fritsch EF and Maniatis T. Molecular Cloning: A Laboratory Manual.1989 Cold Spring Harbor Laboratory Press, Nova York

11. Sathananthan AH, Bongso A, Ng SC. et al. Ultrastructure of preimplantation human embryos co-cultured with human ampullary cells. Hum. Reprod. 1990; 5: 309-318

12. St John J.The control of mtDNA replication during differentiation and development.BiochimBiophys. Acta 2014; 1840:1345-1354.

13. Van Blerkom J, Davis PW, Lee J. Fertilization and early embryology: ATP content of human oocytes and developmental potential and outcome after in-vitro fertilization and embryo transfer. Hum Reprod. 1995; 10:415-424.

14. Vergouw CG, Kieslinger DC, Kostelijk EH, Botros LL, Schats R, Hompes PG, Sakkas D, Lambalk CB. Day 3 embryo selection bymetabolomic profiling of culturemediumwith near-infrared spectroscopy as an adjunct tomorphology: a randomized controlled trial. Hum Reprod 2012; 27:2304-2311.

15. Wilding M, Dale B, Marino M, Di Matteo L, Alviggi C, Pisaturo ML, Lombardi L, De Placido G. Mitochondrial aggregation patterns and activity in human oocytes and preimplantation embryos. Hum Reprod. 2001; 16: $909-917$.

16. Pereda J, Croxatto HB. Ultrastructure of a seven-cell human embryo. Biol Reprod. 1978; 18:481-489

17. Lehtonen E. Changes in cell dimensions and intercellular contacts during cleavage-stage cell cycles in mouse embryonic cells. J Embryol Exp Morphol. 1980; 58:231-249.

18. Stigliani S; Anserini P; Venturini PL; ScaruffI P.: "Mitochondrial DNA content in embryo culture medium is significantly associated with human embryo fragmentation", Human Reproduction. 2013; 28(10): 2652 - 2660. 